\title{
Procedimentos Minimamente Invasivos: Complicações Também Minimizadas ou Subestimadas?
}

A incorporação de técnicas minimamente invasivas à pratica cirúrgica de forma geral, e em especial à Cirurgia Torácica, se constituiu num grande avanço. Inúmeros têm sido os benefícios que podem ser oferecidos aos pacientes, com grande ganho em recuperação e retorno precoce à vida normal. Entretanto, tal é o apelo proporcionado por essas novas técnicas que quase se pode falar em uma perigosa"tendência" a minimizar tudo!

0 fato de que uma técnica cirúrgica clássica possa ser substituída por outra "minimamente invasiva" não significa que a afecção que vai ser tratada, tampouco as possíveis complicações decorrentes, também tenham se "minimizado". Deve-se ter em mente que os preceitos cirúrgicos que regem o tratamento são rigorosamente os mesmos, seja na utilização de técnica cirúrgica clássica ou minimamente invasiva.

O número de maio/junho deste ano do J BP traz dois artigos que merecem comentário não pela simples utilização de técnicas minimamente invasivas, mas pelo teor das conclusões desses trabalhos.

No primeiro deles, Dualibe et al. ${ }^{(1)}$ relatam sua experiência com o tratamento do empiema pleural através de toracocentese, irrigação do espaço pleural e uso de antimicrobiano intrapleural. Em 10 dos 15 casos tratados havia septações pleurais.

0 tratamento de empiema pleural através de toracocentese não é método novo e é descrito nos tratados de cirurgia torácica(2). Entretanto, a sua indicação é muito restrita, para casos selecionados, e principalmente para pacientes nos quais não haja septações do empiema. A presença das septações se constitui numa grave ameaça ao sucesso do tratamento porque podem ser áreas de manutenção do foco de infecção, que impedem a total expansão pulmonar, e que podem evoluir para um quadro séptico e/ou para um encarceramento pulmonar. No mínimo, podem retardar em muito a cura do paciente. Isso é compatível com a descrição dos autores de que $26,67 \%$ dos casos evoluíram com espessamento pleural e que 0 tempo médio de internação foi de 15,1 dias.

No sentido de se evitar esses problemas, 0 Serviço de Cirurgia Torácica do HC adota como conduta nos casos de coleções pleurais septadas a drenagem torácica através de toracoscopia, simples ou videoassistida(3).

Isso assegura que as septações sejam debridadas, a cavidade é limpa e biopsiada, e a drenagem realizada sob visão direta, o que garante a maior chance de cura no mais curto espaço de tempo.

No segundo trabalho, Park et al ${ }^{(4)}$ descrevem sua experiência com 78 casos de traqueostomia percutânea realizados numa unidade de terapia intensiva clínica.

Apesar do detalhamento da descrição da monitorização dos pacientes e dos preparos pré e transoperatórios, não foi relatado sobre quais anéis traqueais foram realizadas as traqueostomias. $\mathrm{E}$ esse é um ponto fundamental na realização do procedimento.

Uma das mais graves complicações da traqueostomia é a estenose da via aérea. Caso essa estenose comprometa a cartilagem cricóide estaremos diante de uma estenose subglótica cujo tratamento é muito mais complicado do que de uma estenose traqueal. Por isso, é fundamental que, da mesma forma que se faz na técnica cirúrgica clássica, se procure realizar a traqueostomia entre $02^{\circ}$ e $03^{\circ}$ anéis traquéais no sentido de se afastar a lesão cirúrgica da cartilagem cricóide.

Esse fato cria dificuldades adicionais. Além da traquéia se localizar mais profundamente no pescoço ao nível do 20 e 30 anéis, essa área se encontra recoberta pelo istmo da glândula tireóide, que também deve ser evitado. Tanto isso é verdade que no início de suas experiências, até mesmo Ciaglia $^{(6)}$ e riggs $^{(7)}$ que foram os introdutores das técnicas, realizavam a traqueostomia no espaço entre a cricóide e $01^{10}$ anel. Somente mais tarde com o aumento da experiência, e principalmente com a introdução da broncoscopia para guiar o procedimento, é que se adequaram as técnicas. 
Por isso a afirmação de que a traqueostomia, classicamente um procedimento cirúrgico na técnica habitual, "vem sendo substituída por manipulações simples que envolvem basicamente a punção e dilatação da traquéia e das partes moles adjacentes" nos parece inadequada por subestimar os possíveis riscos decorrentes do procedimento. Além disso, como as complicações mais graves da traqueostomia, como a estenose ou a fístula traqueo-inominada, costumam surgir tardiamente, parece precoce concluir sem o seguimento a longo prazo desses doentes, que "se trata de um procedimento factível e com poucas complicações sérias que possam trazer riscos maiores aos pacientes". Tanto essa tem sido nossa preocupação, que em nosso Serviço estamos conduzindo um estudo que avalia os pacientes da nossa casuística de cerca de 860 casos, buscando identificar endoscopicamente as possíveis complicações tardias das vias aéreas.

Finalmente, em que pese os bons resultados relatados pelos autores nos seus respectivos trabalhos, devemos ter sempre presente que independente da técnica utilizada, tanto a traqueostomia quanto o tratamento do empiema pleural, continuam sendo tratamentos cirúrgicos, não podendo como afirmam Dualibe et al., haver a " possibilidade abordagem por profissionais sem treinamento cirúrgico".

\section{MIGUEL LIA TEDDE, FABIO BISCEGLI JATENE}

Faculdade de Medicina da Universidade de São Paulo, FMUSP

\section{REFERÊNCIAS}

1. Dualibe LP, Donatti MI, Muller PT, Dobashi PN. Toracocentese esvaziadora com irrigacao e uso de antimicrobiano intrapleural no tratamento do empiema. J BP 2004:Vol 30, no 3: 215-22.

2. Paris F, Deslauriers J, Calvo V. Empyema and bronchopleural fistula. In: Pearson FG; Cooper JD; Deslauriers J; Ginsberg RJ; Hiebert CA; Patterson GA; Urschel, Jr. HC. Thoracic Surgery. Second Edition. Philadelphia: Churchill Livingstone; 2002. Chapter 41, p. 1171-94

3. Tedde $M L$, Minamoto $H$. Drenagem pleural. In: Vargas FS, Teixeira LR, Marques E. Derrame pleural. 10 edição. São Paulo: Roca; 2004. Cap 53:483-4.

4. Park M, Brauer L, Sanga RR, Amaral ACKB, Ladeira JC, Azevedo LCP, Tanigushi LU, Cruz Neto LM. Traqueostomia percutânea no doente critico: a experiência de uma unidade de terapia intensiva. JBP 2004:Vol 30:237-42.

5. Tedde ML, Gregório MG, Jatene FB. Traqueostomia percutânea. In: Silva LCC. Endoscopia Respiratória. 1 ạ edição. Rio de Janeiro: Revinter; 2002. Cap 54, p. 259-63.

6. Ciaglia P, Firsching R, Syniec C. Elective Percutaneous Dilatational Tracheostomy. A New Bedside Procedure; Preliminary Report. Chest 1985: Vol 87:715-9.

7. Griggs WM, Worthley LIG, Gilligan JE, Thomas PD, Myburg JA. A simple percutaneous tracheostomy technique. SGO 1990. Vol 170p. 543-5. 